\title{
Evaluation of Drug Toxicity for DNA Vaccine Candidates Against Infectious Diseases: Hepatitis C as Experimental Model
}

\author{
Dania Bacardí, Karelia Cosme, José Suárez, \\ Yalena Amador-Cañizares and Santiago Dueñas-Carrera \\ Center for Genetic Engineering and Biotechnology, \\ Cuba
}

\section{Introduction}

Progress in the field of biotechnology has accelerated the development of a broad range of novel vaccines, and the composition of vaccine products has evolved from attenuated or inactivated whole-cell organisms, to protein polysaccharide conjugates, peptides, recombinant proteins, DNA vaccines and viral vectors. More recently, there has been a generation of a wide range of complex vaccine products and vaccine technologies (Buckland, 2005) that are often combined with novel adjuvants (Kovarik \& Siegrist, 2001; Litvinov, 2009), administered in new delivery systems, and by new routes of inoculation.

In this context, DNA immunization has arisen as a promising strategy for the development of successful vaccines against infectious agents. In fact, some DNA vaccines have been already registered for application in animals (horses, fishes and dogs) against infection with West Nile virus, Infectious haematopoietic necrosis virus or treating melanoma (Liu, 2011). Moreover, thousands of people have already received DNA vaccine candidates in clinical trials without major adverse events (Alvarez-Lajonchere \& Dueñas-Carrera, 2009).

DNA vaccination involves the administration of DNA, generally but not always a plasmid, to a host in order to induce a desired immune response. Once into the host, the DNA is taken up by cells, including antigen presenting cells, and the protein(s) expected to be the target of the immune system is/are expressed, processed and presented to specialized cells for induction of immune response. For this purpose, the DNA vaccine must comprise an eukaryotic expression unit, encompassing an enhancer/promoter region, intron, signal sequence, vaccine gene and a transcriptional terminator (poly A), for driving protein synthesis in the host (Glenting \& Wessels, 2005). Frequently, DNA vaccines also include immune stimulatory sequences (ISS) for adding adjuvanticity (Glenting \& Wessels, 2005). In addition, a unit for the previous propagation of the DNA in the microbial host, in order to obtain the required amounts for vaccination, is normally present, although some compact variants of DNA vaccines are designed for lacking this unit in the final product (Liu, 2011).

DNA immunization has many possible advantages. No dangerous infectious agents are involved, while the expression of the antigen of interest, in its native form, is possible. DNA vaccines can induce innate and adaptive, both humoral and cell mediated, immune 
responses. There is a potential for encoding multiple immunogenic epitopes with the purpose of raising protection against several diseases by a single vaccine. Compared with many conventional vaccines, DNA vaccines are relatively stable. Moreover, DNA vaccines are rapid to construct and their manufacture is generic (Liu, 2011).

The above mentioned advantages have resulted attractive for the application of DNA vaccination in the infectious disease field in humans. This immunization strategy has been widely evaluated against a variety of human pathogens; some of them without a current vaccine solution available like hepatitis $\mathrm{C}$ virus (HCV) and human immunodeficiency virus (HIV). In fact, DNA immunization has even reached the phase of clinical evaluation in several infectious diseases (Table 1).

The mechanism of action for DNA vaccines and their potential use for therapeutic and preventive purposes imposes relevant challenges for the evaluation of their safety. In addition, knowledge about potential undesirable side effects at long term is still limited. So far, all DNA vaccine candidates entering to clinical evaluation in humans have been previously evaluated for immunogenicity and toxicity in animal models with good results. However, immunogenicity in humans of naked DNA vaccine candidates has not generally fulfilled the expectations. Therefore, several strategies are currently being evaluated for enhancing the immune response, but some of them involve incorporation of components which are potentially able to also increase the toxicity, or might raise the risk for noncontrolled or non-desired immune responses. Consequently, evaluation of toxicity related to DNA-based immunization is a continuously challenged field.

\begin{tabular}{l}
\hline Infectious disease \\
\hline HIV \\
Influenza \\
Malaria \\
HBV \\
HCV \\
SARS \\
Marburg \\
Ebola \\
HPV \\
West Nile virus \\
Dengue \\
HSV \\
Measles
\end{tabular}

Table 1. Infectious diseases for which DNA vaccines have entered to clinical trials

In this chapter we discuss relevant elements to be considered during the evaluation of toxicity related to DNA vaccines applied to infectious diseases. We will focus on local reactogenicity and systemic toxicity studies, biodistribution, persistence, and integration analysis, as well as immune-related studies for detecting potential adverse events after immunization with DNA-based vaccines candidates against $\mathrm{HCV}$, as a model. We focus on $\mathrm{HCV}$ infection since it is a worldwide health problem, causing chronic hepatitis, frequently progressing to cirrhosis and hepatocellular carcinoma. There is no currently available 
vaccine against this pathogen and current therapies are generally effective in only approximately half of patients treated (Ghany et al., 2009). However, some vaccine candidates against HCV are being currently evaluated on clinical trials; two of them being based on DNA immunization (reviewed by Alvarez-Lajonchere \& Dueñas-Carrera, 2009).

\section{Safety evaluation}

In addition to immunogenicity demonstration, regulatory agencies require sufficient preclinical data supporting safety to approve initiation of clinical trials of novel vaccines, including DNA vaccine candidates. The regulatory frame has been abundantly settled (Guidelines for assuring the quality of DNA vaccines, 1998; Guidelines on clinical evaluation of vaccines: regulatory expectations, 2004; Guidelines on nonclinical evaluation of vaccines, 2006). Precisely, the principal aim of non-clinical safety examination is to understand the toxicity of the candidate drug well enough to make judgment that the risk/benefits profile is adequate to initiate clinical trials (Contrera, 1993). Toxicity is complex, and impacted by several factors, such as: the xenobiotic, the dosage, the route, the action mechanism and the products of biotransformation. The distribution of many xenobiotics in the body may only affect certain key organs. Others, however, may damage any cell or tissue it enters in contact with. In addition, the toxicity can result in cellular/biochemical or adverse macromolecular changes. Some examples are: cell substitution, as fibrosis; damage to an enzyme system; interruption of protein synthesis; production of undesired chemical reagents in the cells and damages in the DNA. The distribution of toxic substances and toxic metabolites in the whole body determines the organs and tissues where the toxicity is produced. Many toxic substances are stored in the body, and the most common deposits of storage are fatty structures, the bones and highly vacularized organs involved in blood detoxification, such as the liver and the kidneys.

The safety evaluation involves the experimental studies directed to determine the toxicity, identifying and quantifying effects and establishing parameters (as dose, toxic and lethal concentrations, etc.) of the substances, using in vivo or in vitro models. With the information provided by these studies and other data, the Evaluation and the Estimate of the Risk are carried out, as determination of the probability and nature of the effects that can be derived from the exposition to the xenobiotics.

As for other vaccination strategies, evaluation of safety in the case of DNA immunization requires several considerations and tests. The lots of vaccine candidates to be used in preclinical studies should have been released according to the specifications required for their use in humans. Manufacturers need to establish a reproducible process for producing the DNA vaccine candidate in a sterile and free of endotoxins condition.

The main challenge in establishing a predictive non-clinical safety assessment comes from the fact that vaccines act through complex multi-stage mechanisms. Thus, the detection of the toxicity of vaccines is likely to be more complex than for conventional chemicallyderived drug products, because safety concerns regarding the immune response to the vaccine add to the general concerns related to exogenous substances administration. Thus, toxicity testing programs recommended for conventional drug products may not always be applicable to vaccine products.

The non-clinical safety assessment of vaccines represents a new and evolving field. And clearly, consensus is needed among industry, academia, and regulatory authorities regarding the most appropriate approaches to this area. Depending on the target population 
and vaccine indication, it may be necessary to conduct special non-clinical safety assessments. In particular, if a target population for the product includes pregnant women or females of reproductive age, reproductive toxicity studies should be considered. A global picture of the pre-clinical studies suggested for DNA vaccines is shown in Table 2.

\begin{tabular}{|c|c|}
\hline Type of study & By guideline (EMEA. CPMP/SWP/112/98, 1998) \\
\hline Single dose toxicity & $\begin{array}{l}\text { Should incorporate some safety pharmacology endpoints, and } \\
\text { investigate potential efficacy and toxicological consequences where } \\
\text { systemic exposure is maximized. }\end{array}$ \\
\hline Repeated dose toxicity & $\begin{array}{l}\text { It will be required where multiple dosing of human subjects is } \\
\text { intended. The route, mode, frequency and duration of administration } \\
\text { in the animal studies should mimic the clinical dosing regimen. Where } \\
\text { the duration of treatment of patients is long-term, toxicity studies } \\
\text { should generally be of } 6 \text { months duration. The duration of the } \\
\text { recovery phase investigations should be based on the persistence of } \\
\text { the gene therapy product and expression of gene product }\end{array}$ \\
\hline Immunotoxicity & $\begin{array}{l}\text { The potential for stimulating cell mediated or humoral immunity to } \\
\text { the nucleic acid, the vector-derived material (e.g. viral protein) or the } \\
\text { expressed protein should be investigated. } \\
\text { The potential production of anti-DNA antibodies upon nucleic acid } \\
\text { administration should be addressed because they could mediate } \\
\text { resistance to treatment and/or signal the development of } \\
\text { autoimmunity. Formation of neutralizing antibodies to the gene } \\
\text { construct, its vector or the expressed gene product should be studied } \\
\text { as it may reduce efficacy. }\end{array}$ \\
\hline $\begin{array}{l}\text { Reproduction and } \\
\text { developmental toxicity } \\
\text { studies }\end{array}$ & $\begin{array}{l}\text { Embryo-fetal and perinatal toxicity studies may be required } \\
\text { depending on the disease and clinical population to be treated, if } \\
\text { women of child-bearing potential are to be exposed to gene therapy } \\
\text { products. }\end{array}$ \\
\hline $\begin{array}{l}\text { Genotoxicity and } \\
\text { Carcinogenicity/ } \\
\text { oncogenicity/tumorigeni } \\
\text { city studies }\end{array}$ & $\begin{array}{l}\text { Standard genotoxicity or life-time rodent carcinogenicity studies are } \\
\text { not generally required. Depending on the extent of integration of DNA } \\
\text { into the host genome and the clinical indication, studies may be } \\
\text { required to investigate the potential for tumor formation or disruption } \\
\text { of normal gene expression. }\end{array}$ \\
\hline Distribution & $\begin{array}{l}\text { Studies should provide data on all organs, whether target or not. } \\
\text { Observation time should cover persistence of signal (i.e. duration of } \\
\text { transgene expression and activity) and include time-points for which } \\
\text { there is no signal detection, if applicable. The dosing should mimic the } \\
\text { clinical use with appropriate safety margins. }\end{array}$ \\
\hline Integration studies & $\begin{array}{l}\text { Depending on the proposed clinical use (e.g., non-life threatening } \\
\text { disease or pediatric use). The likelihood and the possible consequences } \\
\text { of vector integration should be evaluated and measures to control } \\
\text { potential associated risks should be described and justified. }\end{array}$ \\
\hline Local tolerance & $\begin{array}{l}\text { A local tolerance study may be required in an appropriate species. } \\
\text { However, if the proposed clinical formulation and route of } \\
\text { administration have been examined in other animal studies then } \\
\text { separate local tolerance studies are not necessary. }\end{array}$ \\
\hline
\end{tabular}

Table 2. Pre-clinical studies indicated for DNA vaccines 
The toxicological studies in animals constitute one of the main sources of information to study the toxicity of chemical compounds and biotechnology products, including vaccines. DNA vaccines evaluated in toxicological studies should comply with good manufacturing practices (Good manufacturing practices for biological products, 1992; Good manufacturing practices for pharmaceutical products, 2003). In these studies, even the less evident effects of the acute and chronic exposition can be generally evaluated easily. In these assays, the capacity to manipulate the experimental conditions allows the evaluation of many variables in response to toxic substances. These studies are very important to predict the toxicity effects in human susceptible populations. However, important limitations should be remarked regarding to the uncertainty of extrapolation from animals to humans. Particularly, it is difficult to extrapolate data obtained with high dose in animals, to the prospective toxicity of the relatively much smaller administration of therapeutic dose in humans.

The selection of the doses, duration and frequency of the dosage should be based on the proposed clinical regime; the levels and duration of the genetic expression in animal experimental models and in humans should also be considered. Typically, pre-clinical studies are carried out in rodents (mice or rats) and rabbits in a general toxicology "screening" base. Such studies are designed to identify both, intrinsic toxicity of the vaccine candidate, as well as immunotoxicity arising from the host immune response after its administration.

Accumulated data uniformly suggest that DNA vaccines are safe (reviewed by Liu, 2011). Mice and rats have been usually used as "first" species to study the toxicity of DNA vaccines. However, the reliability of a particular animal model in predicting an adverse clinical outcome cannot be established. In addition, the effect of vaccines does not exactly scale up directly on body weight or body surface area, since DNA vaccine candidates are expected to act mostly at the local site of administration to induce an immune response that traffics systemically. For this reason, rabbits are frequently used as "confirmatory" species to evaluate acute and chronic toxicity of DNA vaccine candidates since they are animals large enough to receive a full human dose of the vaccine candidate.

According to current Guidance, local reactogenicity and systemic toxicity studies should test the highest dose of the vaccine candidate planned for human use. In addition, N+1 administrations of the vaccine candidate should be delivered in these studies, with respect to the planned number of immunizations to be applied in humans. Recommended analysis include serum chemistry, haematology and coagulation test, in addition to gross and microscopic histology of different organs, particularly those potentially targeted by DNA immunization. Short-term and persistent toxicity are suggested to be evaluated in separate cohorts of animals 2-3 days and 2-3 weeks after final vaccination.

The U.S. Pharmaceutical Research and Manufacturers Association has recommended that non-clinical toxicologic evaluations should be decided case by case (Stoll, 1987) and regulatory and industry representatives attending the first International Conference on Harmonization of Technical Requirements for Registration of Pharmaceuticals for Human Use also supported this position (ICH, 1997).

\subsection{Studies of acute toxicity}

From the regulatory point of view, the information provided by the study of acute toxicity is essential for the classification, manipulation and transportation of a product. From the 
academic point of view, a carefully designed study of acute toxicity provides important information on the mechanism of toxicity, the relationship structure-activity and for the medical warning in the event of poisoning (based on the observed toxic effects (Chan \& Hayes, 2001).

In general, these assessments include the evaluation of the oral, dermal and inhalator toxicity, as well as dermal and ophthalmic irritability, all of them guided by international regulations. Other studies should be kept in mind like the pre-natal and post-natal exposition, sensitization and phototoxicity. Depending on different scientific factors, the number and type of necessary acute tests to establish the initial toxicity may vary from a compound to another (Chan \& Hayes, 2001; OECD Guidelines for testing of chemicals, 1993). A battery of studies should be designed under different conditions and exposition routes.

The objectives of this type of studies are:

1. to define the intrinsic toxicity of a compound.

2. to evaluate the danger at the target and not target species.

3. to define the most susceptible species.

4. to identify target organs.

5. to provide information for designing and selecting the dose levels for the long term studies.

6. to offer information to the clinical researcher in order to predict, diagnose, and prescribe the treatment for the over exposition to any drugs.

In the case of vaccine regulation, it establishes the employment of at least one animal species, which will be receiving high dose levels for providing an appropriate margin of security in relation to the dose expected to be applied in humans. Therefore, with the toxic signs found in this assessment, the relationship dose-response should be broadly characterized. The histopathology study of the key organs should be also included.

Here, as example, we show some data obtained in an acute toxicity study with CIGB-230, a DNA vaccine candidate, based on a plasmid for DNA immunization expressing HCV structural antigens (Alvarez-Lajonchere et al., 2006), which was planned to be used as a therapeutic vaccine candidate in $\mathrm{HCV}$-infected patients.

In the acute toxicity study, carried out in Sprague-Dawley rats, we explored the effect of intramuscular injection with a high dose of the vaccine candidate CIGB-230, and the application of up to 90 times the planned therapeutic dose to be evaluated in the clinical setting. There were six working groups, 10 animals each (5 females and 5 males); group I: normal saline (control); group II: placebo of GIGB-230 (control); group III: plasmid pIDKE2 in high dose (90 times the planned therapeutic dose); group IV: CIGB-230 in high dose 1 (30 times the planned therapeutic dose); group V: CIGB-230 in high dose 2 (60 times the planned therapeutic dose); group VI: CIGB-230 in high dose 3 (90 times the planned therapeutic dose). The animals consumed food (Figure 1) within the ranks established for the species, which was translated in a progressive increase in body weight in both males and females (Figure 2).

The signs more frequently found were the extramedular hematopoiesis and lymphoid hyperplasia in the spleen, as well as the presence of secondary follicles in the ganglion (Table 3). The first one of these signs has been reported as frequently detected in this species, in which hematopoietic reserve is limited, causing that frequently the spleen and the liver assume this function in a complementary way (Loeb et al., 1978; Greaves, 2000). The 
presence of lymphoid hyperplasia and of secondary follicles is an indicative of the appropriate function of these organs of the immune system (spleen, liver and inguinal ganglion), demonstrating that, as expected, the treatment with the vaccine candidate in study does not alter the cellular morphology, neither the function of these organs.

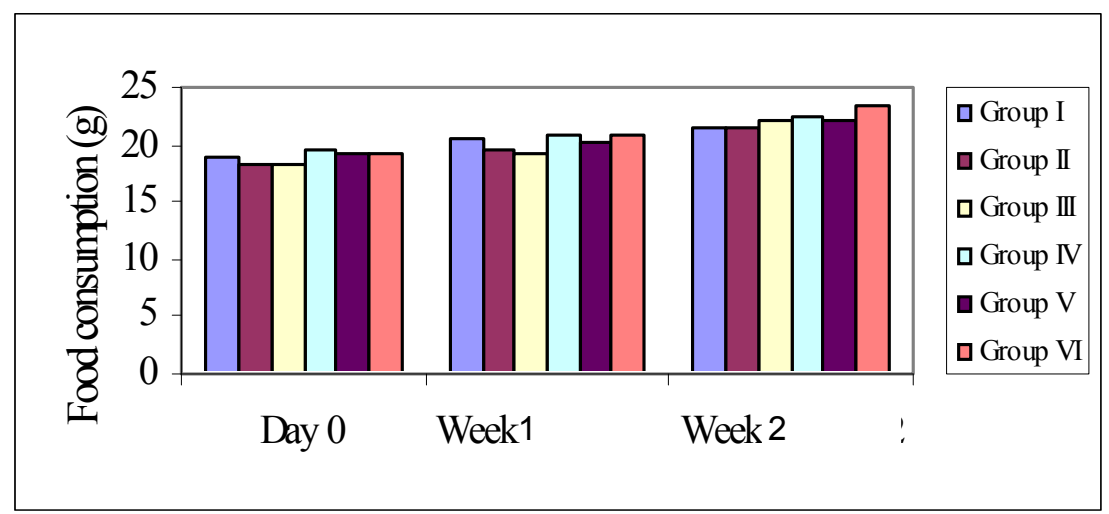

Fig. 1. Behavior of average food consumption in Sprague-Dawley rats. Ten animals per group ( 5 females and 5 males); group I: normal saline (control); group II: placebo of GIGB230 (control); group III: plasmid pIDKE2 in high dose (90 times the planned therapeutic dose); group IV: CIGB-230 in high dose 1 (30 times the planned therapeutic dose); group V: CIGB-230 in high dose 2 (60 times the planned therapeutic dose); group VI: CIGB-230 in high dose 3 (90 times the planned therapeutic dose).

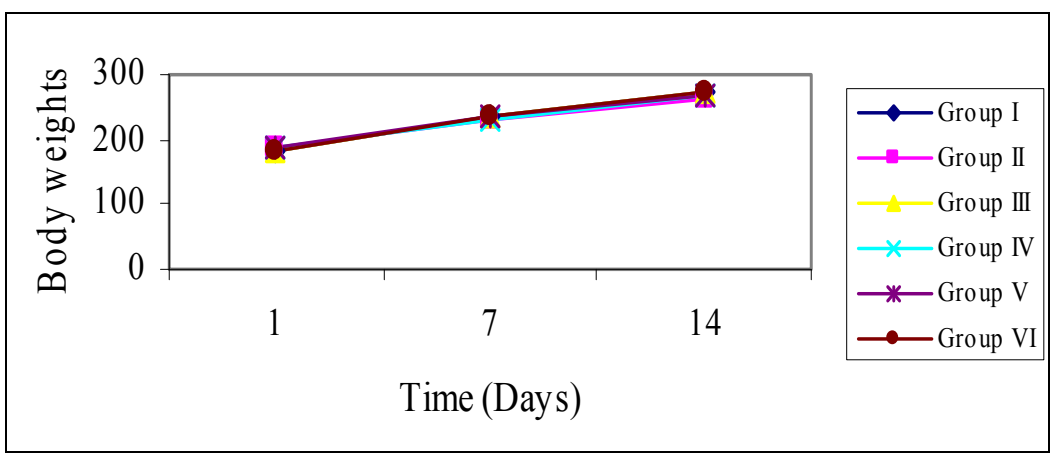

Fig. 2. Behavior of animal body weight (g). Ten animals per group (5 females and 5 males); group I: normal saline (control); group II: placebo of GIGB-230 (control); group III: plasmid pIDKE2 in high dose (90 times the planned therapeutic dose); group IV: CIGB-230 in high dose 1 (30 times the planned therapeutic dose); group V: CIGB-230 in high dose 2 (60 times the planned therapeutic dose); group VI: CIGB-230 in high dose 3 (90 times the planned therapeutic dose). 
Another finding observed in spleen was the presence of a germinal center. Given the greater frequency of detection of this sign in the group inoculated with saline solution, it is not probably related with CIGB-230.

\begin{tabular}{|c|c|c|c|c|c|c|c|}
\hline \multirow{2}{*}{ Group } & $\begin{array}{c}\text { Administration } \\
\text { Site }\end{array}$ & \multicolumn{3}{|c|}{ Spleen } & Mesenteric Ganglion & \multicolumn{2}{c|}{ Liver } \\
\cline { 2 - 8 } & IF & CG & HE & HL & FS & FN & Mg \\
\hline I & $0 / 10$ & $5 / 10$ & $2 / 10$ & $1 / 10$ & $10 / 10$ & $3 / 10$ & $0 / 10$ \\
\hline II & $0 / 10$ & $2 / 10$ & $0 / 10$ & $3 / 10$ & $10 / 10$ & $0 / 10$ & $0 / 10$ \\
\hline III & $0 / 10$ & $1 / 10$ & $0 / 10$ & $6 / 10$ & $10 / 10$ & $2 / 10$ & $0 / 10$ \\
\hline IV & $0 / 10$ & $1 / 10$ & $4 / 10$ & $8 / 10$ & $10 / 10$ & $1 / 10$ & $1 / 10$ \\
\hline V & $1 / 10$ & $1 / 10$ & $4 / 10$ & $8 / 10$ & $10 / 10$ & $0 / 10$ & $0 / 10$ \\
\hline VI & $0 / 10$ & $3 / 10$ & $0 / 10$ & $3 / 10$ & $10 / 10$ & $0 / 10$ & $0 / 10$ \\
\hline
\end{tabular}

Legend: HE: Extra-medular hematopoiesis, FN: Centers of necrosis, HL: Lynphoid hyperplasia, Cg: Germinal center, Mg: Microgranulome, FS: Secondary follicle, IF: lymphohistocitary focal Infiltrated

Table 3. Frequency of detection of microscopic findings by organ observed and treatment group.

The thymus showed normal morphology, without evidences of cellular depletion, which corroborates the functionality of this organ, non-altered with the applied treatments. In fact, in the studied lymphoid organs histopathological alterations were not observed, showing reactions common to the antigenic stimulation, characterized by germinal centers at the level of the cortical area in ganglion and in the spleen white pulp.

The site of administration was also object of histopathological study, given the importance of the evaluation of the local response in this type of vaccine. Only one animal in the group $\mathrm{V}$, injected with 60 times the therapeutic dose, presented a lymphohistocitary infiltrate.

Therefore, the study evidenced only some minor findings that were produced by nonspecific causes, not related to the administration of the vaccine candidate, or in other cases, findings that are the result of antigenic stimulation, as expected response to the immunization, which is far to be an adverse event, on the contrary, corroborates the pharmacological action of the product and demonstrates that it does not produce undesired alterations on the immune system. The vaccine candidate CIGB-230 did not cause adverse effects or evidenced signs of toxicity for the dosage used, including the maximum dose inoculated (90 times the planned therapeutic dose)

\subsection{Studies of local tolerance}

The purpose of these studies is to check if the active pharmaceutical ingredient, as well as the excipients, are tolerated in those sites that can be in contact with the medication during the period of application in humans, taking into consideration the administration ways, either accidental or planned as treatment régime. The outlined design in each schedule should distinguish between the traumatic effects as consequence of the administration and those that are derived of the product under evaluation (toxicological or pharmacodynamic effects).

In the studies of local tolerance, the frequency, duration and way of administration should consider the proposed clinical evaluation in humans. Nevertheless, the period of 
administration should not exceed the four weeks (ICH M3 (M), 2000; The principles governing medical products to the European Community, 1992).

As vaccines in most cases are administered by intramuscular, subcutaneous or intracutaneous way, the local tolerance in the application site should always be evaluated, using the same formulation that will be administered in the clinical evaluation in humans. In many cases, the potential local effects of the product can be evaluated in the studies to unique dose and of toxicity to repeated dose, but obviously it is necessary to evaluate the local tolerance for separate.

As illustration, here we show some data related to the local tolerance study carried out to the vaccine candidate CIGB-230. In this design, CIGB-230 vaccine candidate and the plasmid pIDKE2, component of this formulation, were used as substance in study. The groups of treatment were: control, inoculated with normal saline; placebo; and groups with CIGB-230 vaccine candidate using 1, 10 and 30 times the therapeutic dose, as well as the satellite group inoculated with 30 times the therapeutic dose. Six inoculations, 72 hours apart, were carried out in all treatment groups. After inoculations, all animals were sacrificed except those corresponding to the satellite group that stayed under clinical observation in order to evaluate the reversion of the possible observed effects. Clinical observation was carried out during 19 days (groups I to VI). In the case of the satellite group, the clinical observation was carried out up to day 40 of the experimental phase. Macroscopic observation and sample extraction was performed during necropsy, in order to evaluate the histopathology at the administration site and other organs, at the moment of the animal sacrifice.

\begin{tabular}{|c|c|c|c|c|}
\hline \multirow{2}{*}{ Group } & Spleen & Liver & Mesenteric ganglion & Administration site \\
\cline { 2 - 5 } & HL & FN & FS & IFHL \\
\hline I & $4 / 5$ & $1 / 5$ & $5 / 5$ & $0 / 5$ \\
\hline II & $4 / 5$ & $1 / 5$ & $5 / 5$ & $4 / 5$ \\
\hline \hline III & $4 / 5$ & $0 / 5$ & $5 / 5$ & $3 / 5$ \\
\hline IV & $5 / 5$ & $0 / 5$ & $5 / 5$ & $5 / 5$ \\
\hline V & $3 / 5$ & $0 / 5$ & $5 / 5$ & $5 / 5$ \\
\hline \hline VI & $5 / 5$ & $0 / 5$ & $5 / 5$ & $5 / 5$ \\
\hline VII & $5 / 5$ & $1 / 5$ & $5 / 5$ & $0 / 5$ \\
\hline
\end{tabular}

Group I: normal saline (control); group II: placebo of GIGB-230 (control); group III: CIGB-230 in the planned therapeutic dose; group IV: CIGB-230 10 times the planned therapeutic dose; group V: CIGB23030 times the planned therapeutic dose; group VI: plasmid pIDKE2 30 times the planned therapeutic dose; group VII: CIGB-230 30 times the planned therapeutic dose (satellite group). Legend:FN: Centers of necrosis, HL: Lymphoid hyperplasia, FS: Secondary follicle, IFHL: lymphohistocitary focal Infiltrate.

Table 4. Frequency of detection of microscopic findings by organ observed and treatment group at day 20.

Animals consumed food according to the standards established for their species, which led to a gradual increase in body weight. There were neither etiological nor anatomical changes. There was a normal response to stimuli in all animals involved in the study. The macroscopic/microscopic observations confirmed the clinical observations and proved there was no damage related to the substance in trial in any organ of the studied animals. In the 
histopathologic study, a predominant cellular response consisting in a focal infiltration of histiocytes, lymphocytes and leukocytes, was observed in all groups of treatment (Table 4 and Figure 3), In the spectrum of doses explored in Sprague-Dawley rats, CIGB-230 vaccine candidate was well tolerated by intramuscular injection.

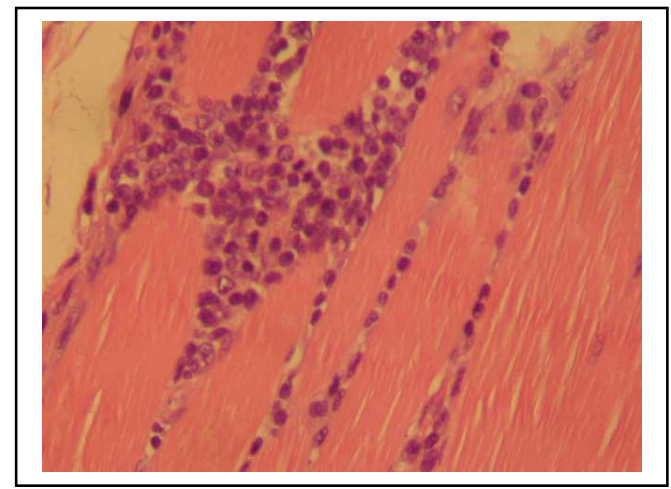

Fig. 3. Lymphohistocitary infiltrate observed in the place of administration of a representative animal.

\subsection{Studies of toxicity to repeated dose}

The studies of toxicity to repeated dose allow showing the wide scenario of adverse effects of a preparation. The time of duration of these studies may vary, generally from 1 to 4 weeks for short term studies, 3 months in the case of subchronic studies and of 6 to 12 months, classified as chronics. Different variables, associated with the health and the behavior of the used animal species, are followed up, resulting in the ability of detecting the adverse effects caused by the preparation under test.

The results obtained from the studies of toxicity to repeated doses play a fundamental role in the evaluation of the safety of medications, pesticides, nutritious preservatives and other preparations. These offer enough information to predict the long term toxicity of a compound administered in low dose, whenever an appropriate relationship structureactivity exists.

For the evaluation of vaccines in studies of toxicity to repeated doses, the employment of animal species carefully selected, to which apply different dose levels of the product under test is usually required. These studies should always be carried out, even in those cases in which single inoculation of the vaccine is expected in humans. The route and administration frequency will be similar to the proposed clinical schedule, keeping in mind the potential differences of the response in the time between animals and humans. Previous works have evidenced the safety of repeated administration of a plasmid DNA vaccine candidate by different routes in various animal models (Parker et al., 1999; Tuomela et al., 2005). A wide range of doses has been evaluated and in all administration methods, DNA vaccines have been well-tolerated and non-toxic.

In the case of CIGB-230, as previously described (Bacardí et al., 2009), no toxic effects were found after repeated intramuscular injection in Sprague-Dawley rats. The study was conformed by 6 groups: a non-treated group, a placebo one, a satellite group and three groups treated with 5, 15 and 50 times the planned therapeutic dose, respectively. The 
satellite group was used to evaluate the reversibility of possible adverse effects, and the non-treated group remained during the whole study with the same lodging and feeding conditions. A daily administration was carried out during 30 days.

Clinical observations led us to confirm the quality of this product; no evidences of ethologic or morphological alterations, which could be attributable to the substance under study, were found. Results from these evaluations proved a normal behavioral pattern in the animals, with feeding consumption rates, weight gain and behavior corresponding to healthy animals of the species, even when they were repeatedly inoculated (30 administrations). This also showed that the repeated administration of the vaccine did not cause metabolic or behavioral alterations which might be translated into adverse effects, thus constituting indirect signals of non-toxicity, given the sensitivity of these parameters to detect alterations produced by the inoculation of exogenous substances. Neither ethologic nor anatomic alterations were observed in the animals used in the study, thus preserving the condition of a normal response versus stimuli in all cases. Macroscopic observations confirmed the clinical observations and evidenced that there was no damage to any of the organs tested. At the time of the clinical pathology assessment (either of hematology or blood biochemistry), no functional and/or structural alterations of tested organs existed. The results suggest full hematopoietic functionality without evidences of alterations produced by the repeated administration of this vaccine candidate. An integral analysis of hemochemical determinations indicates that the repeated inoculation of CIGB-230 in rats does not cause toxic effects on kidneys and liver, which are main target organs given their participation in metabolic and excretion processes (Bacardí et al., 2009).

Histopathological evaluation proved that the single or multiple administration of the product did not induce morphological alterations in the studied organs of rats, also showing full functional morphology in those from the immune system. Therefore, these observations suggest that the inoculation of CIGB-230 does not affect eritropoiesis or the production of white blood cells precursors. Extra-medullar hematopoiesis (mainly observed in the spleen) has been previously described as a result of organ response to moderate stress; additionally, it is a commonly reported finding on this species, which hematopoietic reserve is limited. This finding appeared with equal frequency in the placebo and non-treated group and in those treated with CIGB-230, further supporting its unrelated nature with the administration of the test item. Lymphoid hyperplasia and secondary follicle are signs of adequate functioning of lymphoid organs; this suggests that, as expected, treatment with CIGB-230 does not alter cellular morphology or function of these organs. At the site of administration, most rats showed minimum focal infiltrate of lymphocytes and histiocytes. In the satellite group (VI), the reversion of this finding was observed, because it was present in only four of the animals (Bacardí et al., 2009).

The results demonstrated that CIGB-230 therapeutic vaccine candidate was well tolerated, did not induce either local or systemic adverse alterations at the studied doses, and exhibited no observable toxicity in rats when tested.

\subsection{Biodistribution and persistence}

One major risk related to DNA immunization is distribution to non-desired tissues and organs, as well as potential integration to the host genome. Long-term persistence might facilitate the integration of plasmid DNA into the host's genome. Moreover, long-term expression could cause long-term skewing of the immune system influencing subsequent immunizations and infections. One study found that DNA delivered into mouse muscle was 
stably expressed for 19 months, even though no integration could be detected (Wolff et al., 1992).

The biodistribution and persistence of a DNA vaccine is potentially dependent on the formulation (naked DNA or combined with other elements), route of administration and delivery method and should be evaluated. It is suggested that these studies of biodistribution and persistence should be designed to determine whether subjects in DNA vaccine trials are at risk from the long-term expression of the encoded antigen, and/or integration of the plasmid that might increase susceptibility to malignant transformation.

A typical biodistribution/persistence study assesses the presence of plasmid collected from a panel of tissues at multiple time points ranging from a few days to several months post administration. The panel of tissues typically includes the blood, heart, brain, liver, kidney, bone marrow, ovaries/testes, lung, draining lymph nodes, spleen, muscle at the site of administration and subcutis at the injection site (Guidance for Industry Considerations for Plasmid DNA Vaccines for Infectious Disease Indications, 2007).

Up to now, the results obtained in pre-clinical evaluation of DNA vaccine candidates evidence a consistent pattern of rapid clearance of the plasmid regardless of promoter, backbone or inserted genes (Bureau et al., 2004; Tuomela et al., 2005). Similarly, no evidence of integration into the host genomic DNA has been generally observed (Coelho-Castelo 2006; Pal et al., 2006).

Different animal species have been evaluated for this type of studies (Manam et al., 2000; Parker et al., 1999). A short time after administration of the plasmid DNA in mice, the plasmid can be detected in several organs, some of them far from the inoculation site, which indicates a quick dissemination through the body (Hohlweg \& Doerfler, 2001; Manam et al., 2000). Sporadically, the plasmid was detected in gonads, but it dissipated rapidly (Manam et al., 2000; Parker et al., 1999). Evidently, when plasmid is transmitted to the gonads, germ line chromosomal integration and germ line transmission may occur, although these phenomena have not been observed so far and due to rapid DNA clearance in the gonads, the risk of these events is expected to be minimal.

In fact, several weeks after injection of the DNA construct, the plasmid could only be detected at the site of injection in mice and rats (Manam et al., 2000). DNA injected in mouse muscle has been reported to persist for up to two years and was expressed at a low, but significant level (Armengol et al., 2004), although persistence and expression seems to be variable.

The level of plasmid DNA at the injection site has been below 100 copies/ $\mu$ g DNA after initial injection with 100-200 $\mu$ g DNA (Manam et al., 2000; Parker et al., 1999; Tuomela et al., 2005). Previous work has shown that 30 minutes after intramuscular injection $33 \%$ of the initial concentration was present and 60 minutes later less than $1 \%$ remained (Kim et al., 2003). The amount of plasmid DNA in organs remote from the injection site was 2-3 orders of magnitude lower than at the injection site (Kim et al., 2003). When de administration was carried out by intravenous route, plasmid DNA was initially distributed at a relatively low amount to all tissues examined, except the gonads and brain, in which no plasmid DNA was detected. However, plasmid DNA was rapidly cleared (Parker et al., 1999; Tuomela et al., 2005). Less than $1 \%$ of the initial concentration was detected in blood 30 minutes postadministration in mice, and no plasmid was detected 60 minutes post-administration (Kim et al., 2003). These results indicate that most DNA administered seems to be degraded by extracellular nucleases and only a minor amount is taken up by cells. This situation causes 
that high-dose levels of plasmid are usually required for DNA immunization when naked DNA is employed.

Despite the relatively prolonged antigenic stimuli generated by DNA immunization due to gene expression for a period of time, for therapeutic DNA vaccine candidates against infectious agents several immunizations might be required in order to reach the sustained clearance of the pathogen. In this scenario, DNA might accumulate in higher amounts in the body which increases the risk for undesired events. In such cases, biodistribution and integration studies should be performed, taking into account the predicted immunization schedule in humans.

In the case of CIGB-230, the biodistribution study conducted demonstrated that after repeated intramuscular administration in mice, plasmid was readily detected in blood, as well as in all evaluated organs, except pancreas, as early as $1 \mathrm{~h}$ after inoculation (Bacardí et al., 2009). This wide organ distribution is consistent with the above mentioned results regardless of the animal model or the method and route of administration. So far, the knowledge regarding the actual mechanisms by which administered DNA distributes widely throughout the body is scarce. The DNA is probably efficiently transported to all organs by the blood. In this case, highly vascularized organs, as well as those involved in blood detoxification and recycling, such as the liver and kidneys should receive the highest amount of DNA. We were able to detect plasmid in liver, as well as in kidney samples, $1 \mathrm{~h}$ after the eighth inoculation. However, $17 \mathrm{~h}$ later, the signal could no longer be detected in kidney, whereas it remained in the liver. In this sense, either of two speculations can be raised: 1) clearance kinetics is faster in the kidneys or 2) there is a preference for the plasmid to distribute in greater quantity to the liver in our experimental conditions. Elevated levels of plasmid DNA have been found in the hepatic tissue during the first hours after intravenous (Kobayashi et al., 2001) and intranasal (Oh et al., 2001) inoculation in mice; consequently, the extensive uptake of naked DNA by the liver appears to be a common feature, in which the scavenger receptors play an important role. On the contrary, accumulated data regarding renal tissue are more heterogeneous. Some investigators were not able to detect plasmid copies in the renal tissue after $24 \mathrm{~h}$ of DNA inoculation formulated with poloxamer 188 in mice and rabbits (Quezada et al., 2004), nevertheless other work inoculating DNA-PEI complexes intravenously in mice, detected plasmid in kidneys even several days post-inoculation, evidencing the importance of formulation and route of administration (Jeong et al., 2007).

On the other hand, we observed a rapid diffusion of the plasmid to the ovaries, because it was present at detectable levels $1 \mathrm{~h}$ after the eighth inoculation. At the same time, the clearance kinetic in these organs was fast, because it could not be detected $17 \mathrm{~h}$ later (Bacardi et al., 2009).

Being the injection site for CIGB-230, the muscle receives the highest amount of DNA. As expected, $1 \mathrm{~h}$ after the eighth inoculation we could detect it in the inoculation site. Seventeen hours later, we still detected a positive signal, which persisted 30 days after 7 doses in all the evaluated mice, but it was not detected at a later time (Bacardi et al., 2009). In a previous study (Acosta-Rivero et al., 2006), we could detect HCV E2 protein expression in the muscle cells of the inoculation site as early as $72 \mathrm{~h}$ post-inoculation of CIGB-230 in BALB/c mice, under the same conditions described in the biodistribution study. In addition to the nondetection of the plasmid, three months after the last immunization antigen expression was not detected (Bacardi et al., 2009). 
Several strategies, based on improvement on formulation or delivery vehicles have been or are currently being evaluated as alternative for reducing DNA dose levels or in order to increase immunogenicity of DNA vaccine candidates (Liu, 2011). However, although some of these strategies have succeeded at increasing the ability of DNA to reach the intracellular space as well as enhance immunogenicity, the risk for greater possibility of an undesired integration event is also bigger.

Integration of plasmid DNA into the recipient's genome appears the major point into the safety issues of DNA vaccination. Integration may occur randomly or by homologous recombination and could lead to activation of oncogenes, inactivation of tumor suppressor genes, or, when integrated into the chromosomal DNA of germ line cells, to vertical transmission.

Techniques for sensitive and precise detection of DNA integration have been developed. High molecular weight DNA is isolated and purified from non-integrated plasmid using pulsed-field gel electrophoresis, followed by detection and quantification of the plasmid with real time PCR. A recommendation is given that the sensitivity of this assay be sufficient to quantify $<100$ copies of plasmid per microgram of host DNA. A claim of "nonpersistence" requires that the amount of plasmid at each site falls below this limit of quantification (Guidance for Industry Considerations for Plasmid DNA Vaccines for Infectious Disease Indications, 2007). In a previous work, the sensitivity of the PCR has been approximately 1 plasmid copy per $\mu$ g DNA, representing approximately 150,000 nuclei and all detectable plasmid DNA in treated muscle tissue has been generally extrachromosomal (Ledwith et al., 2000). Thus, random integration might have occurred, but at frequencies of $<1-8$ copies in 150,000 nuclei. (Ledwith et al., 2000), which would be at least three orders of magnitude below the spontaneous mutation rate of gene-inactivating mutations. Therefore, in a case like this, the risk of mutation due to plasmid integration following intramuscular inoculation is negligible.

In contrast to the study mentioned above, Wang et al, using a newly developed PCR assay, identified four independent integration events upon plasmid injection followed by elecroporation in vivo (Wang et al., 2004). This PCR uses a vector-specific primer and a genomic primer based on repetitive DNA. The PCR detects covalent junction of plasmid togenomic DNA sequences after repeated rounds of gel purification to remove free plasmid DNA. Electroporation markedly increased plasmid tissue levels and its association with genomic DNA after gel-purification approximately 980 copies of plasmid DNA were found to be associated with $1 \mu \mathrm{g}$ of high molecular weight genomic DNA, whereas for the muscle DNA samples from non electroporated mice, only 17 copies/ $\mu$ g DNA were found (Wang et al., 2004). Therefore, the risk of DNA integration into the genome exists. Thus, for each new DNA vaccine candidate to be used, integration should be considered. Depending on the extent of integration of DNA into the host genome and the clinical indication, studies may be required to investigate the potential for tumor formation or disruption of normal gene expression.

\subsection{Mutagenicity and carcinogenicity studies}

Studies should be carried out in order to evaluate the potential damage to the host genetic material as consequence from the exposition to the DNA vaccine preparation. Particularly, mutagenicity/carcinogenic studies allow identifying possibly dangerous compounds at this level. 
Tumors can be induced by numerous agents, including radiations, biological agents and chemical substances of diverse origin. Malignant transformation originates from alterations in the cellular genetic program or from changes in the information contained in the cells and its subsequent fixation and replication. Carcinogenicity studies identify these undesired events and are necessary when medications will be administered for 6 months or more in humans, or for those frequently used in an intermittent way in chronic or recurrent treatments. In addition, these tests should be carried out if drugs under evaluation are planned to be administered by short time but there is previous demonstration or known risk of possible carcinogenicity, and accumulation of the product or their metabolites in tissues may rise with possible undesired physiopathologic responses (ICH, 1995).

The experimental design for this type of studies involves carrying out specific evaluations taking into account characteristic of the product, duration of the clinical treatment, target population, biological activity, and expression of receptors in normal and malignant cells. Several established carcinogenicity criteria are increases in malignant tumors in treated animals, increases in the combination of benign and malignant tumors, tumors appearance in non usual sites, rare tumors for the animal species, tumors detection at early ages.

A standard battery of genotoxicity and conventional carcinogenicity studies are not generally applicable to DNA-vaccines. However, genotoxicity studies may be required to address a concern about a specific impurity or novel chemical component, e.g. a complexing material that has not been tested previously (Guidelines for assuring the quality and nonclinical safety evaluation of DNA vaccines, 2005). The main risk for mutagenic/carcinogenic activity for DNA vaccine preparation comes from the persistence of the DNA in the host, and the potential for integration into the genome. Therefore, mutagenic/carcinogenicity studies in DNA vaccination are related to the integration studies and are particularly required if integration events are detected. In addition, for non-naked DNA vaccine preparations, even in the case of non-integration events detected, the presence of potentially dangerous compounds in the preparation should be evaluated according to the above mentioned criteria. This is particularly relevant when DNA vaccine preparation is planned to be employed in several doses or the duration of treatment is expected to be long, like in chronic infectious diseases such as hepatitis B and C.

\subsection{Immunotoxicity}

We recommend that vaccine immunogenicity be assessed in a relevant animal model whenever possible. This may include the evaluation of antigen-specific antibody titers, seroconversion rates, activation of cytokine secreting cells, and/or measures of cellmediated immune responses. In this sense, the immune system represents an important and potential target organ for toxicity, which is similar in organization, cell types and functions in both man and animals, and thus represents a relevant parameter in the risk assessment process.

The mechanism of action in DNA vaccination is the induction of a relevant immune response against a target. Therefore, the way this occurs in the host is very relevant and should be evaluated carefully since undesired effects might arise at the immunological level due to vaccination. Immunotoxicity (e.g. immunosuppression, myelotoxicity, allergy, or autoimmunity) studies are required to assess the immunogenic potential of a product. Some indicative of immune affections should be observed: inflammatory reactions (stimulation), variation in the expression of the surface antigens in target cells (autoinmune potential), and long term immunological effects. 
Published preclinical studies indicate that DNA vaccination can activate autoreactive B cells to secrete IgG anti-DNA autoantibodies. However, the magnitude and duration of this response appears to be insufficient to cause disease in normal animals or accelerate disease in autoimmune-prone mice. Preclinical studies suggest that systemic autoimmunity is unlikely to result from DNA vaccination. Similarly, the absence of an immune response against cells expressing the vaccine-encoded antigen (including muscle cells and dendritic cells) suggests that an autoimmune response directed against tissues in which such cells reside is unlikely. Yet the possibility persists that DNA vaccines might idiosyncratically cause or worsen organ-specific autoimmunity by encoding antigens (including cryptic antigens) that cross-react with self (Guidance for Industry Considerations for Plasmid DNA Vaccines for Infectious Disease Indications, 2007).

In non-clinical and clinical investigations to date, tolerance has not been observed in adult animals and humans, and the initial concern may have been overstated. Tolerance can be induced in neonatal mice; this may be because the mouse immune system at birth is immature. If development of tolerance is a concern for a specific product, a more relevant animal model is desirable.

A case by case approach to evaluate immunotoxicity of DNA vaccines, based on the potential similarity of expressed antigens to natural human proteins and immune response in animal models should be explored. General welfare of animals in preclinical immunogenicity and toxicity studies continue to be carefully monitored. At least limited immunotoxicological assessment should be performed in all toxicity studies. This evaluation is based on two sources of information, one coming from routine toxicity parameters and the other from specific immunological tests in multiple species.

Parameters determined in all the toxicity studies and which enable the toxicologist to detect some aspects of potential immunotoxicity, if present, are the following:

- White blood cells and differential count;

- plasma globulin level;

- routine histopathological examinations. These include: weighing the thymus and spleen, histo-pathological examination of the thymus, spleen, hilar and mesenteric lymph nodes and femoral bone marrow.

- Specific immune parameters are also examined to assist decision making and include:

- femoral bone marrow cellularity (rat only), in all the toxicity studies including the 1month toxicity studies;

- total plasma immunoglobulins (IgG and IgM) in all the species using radial immunodiffusion method, in conjunction with the clinical chemistry examinations; and

- histopathological examination of the popliteal lymph nodes in all the toxicity studies, whatever the species; special attention is paid to all the other lymph nodes which are occasionally present on the slides (retromandibular, parathymic) and to the bronchialand gut-associated lymphoid tissues.

The results of the lymphoid organs and bone marrow histopathological examinations are analyzed together with information from all other organs/tissues. This assists the pathologist to discriminate between primary lymphoid system lesions (direct immunotoxic effect) and secondary lymphoid system lesions (indirect immunotoxic effect). The latter, in the case of treatment-induced stress, can be frequently observed in toxicity studies. These special immunotoxicity studies require careful monitoring of all changes, which are stress and malnutrition status-related information, often neglected in routine histopathological examination. Special immune function tests might be selected and include measurement of 
plaque forming cell (PFC) and serum antibody titers to keyhole lympet hemocyanin (KLH), lymphocyte transformation, mixed lymphocyte responses, blood lymphocyte phenotyping and natural killer cell cytotoxicity (Dean et al., 1998).

Frequently, cytokines are used as immune modulators in DNA immunization, co-expressed to the antigen targeted to elicit immune response or in other variants. In such cases, preclinical studies in animal species responsive to the encoded human cytokine(s) or models using homologous animal gene(s) are encouraged. Such studies should assess whether modulation of cellular or humoral components of the immune system might result in unintended adverse consequences, such as generalized immunosuppression, chronic inflammation, autoimmunity or other immunopathology (Guidance for Industry Considerations for Plasmid DNA Vaccines for Infectious Disease Indications, 2007).

In the therapeutic setting, where DNA vaccination is expected to dramatically change the context of the immune response in order to reach for instance the clearance of a chronic pathogen like $\mathrm{HCV}$, uncontrolled or undesired immune response is a theoretical risk. However, DNA vaccination has been safe and well tolerated, with no evidence of this sideeffect; even when specific immune response has been elicit de novo against HCV antigens (Alvarez-Lajonchere et al., 2009; Castellanos et al., 2010). In general, immunopathological reactions such as general immunosuppression or uncontrolled inflammation have not been observed in humans inoculated with DNA vaccines so far.

\subsection{Study of reproductive function and perinatal toxicity}

These studies intend to give general information on the effects of a substance on the female/male reproductive system, such as gonadal function, estral cycle, behavior of mating, conception, childbirth and nursing. They can be carried out in one or two generations. In these studies, assessment of the growth and development of the descendant is carried out. Teratogenic potential (property of causing permanent structural and functional abnormalities during the period of embryonic development) is also evaluated, as well as any potential danger for the neonate due to exposition of the mother to a substance during pregnancy is also investigated.

Worldwide harmonized guidelines for reproductive testing have been established (ICH (1996): Detection of Toxicity to Reproduction from Medicinal Products; ICH (1996): Reproductive Toxicity: Male Fertility Studies). Generally, animal studies have been conducted in three segments: in adults, in pregnant animals, and in pregnant and lactating animals.

In the case of DNA vaccines against infectious agents, they are expected to be administered to different populations, including people at fertile ages and potentially pregnant women. Therefore, these studies are required before general application of a DNA vaccine. However, these studies may not be required prior to clinical studies in populations with lifethreatening diseases, provided appropriate measures are taken to minimize risks. Prior to use of a DNA vaccine in children or newborns, the product should be tested for safety and immunogenicity in adults, and appropriate nonclinical models, e.g. with juvenile animals, should be considered regarding toxicity and induction of immunological tolerance.

\subsection{Final general recommendations for safety evaluation of DNA vaccine candidates}

A generic protocol is not provided, but general recommendations are described below: 
a. The choice of animal model should be appropriate for the product and clinical indication. Often rabbits are used for parenteral vaccine toxicity because their muscle mass may receive a volume equivalent to a full human clinical dose (e.g., $0.5 \mathrm{~mL}$ ).

b. High dose should be at least 1 - 10 times the actual highest planned clinical dose; sometimes preferably not scaled on weight or body area.

c. To determine if the observed effects are dose-related (and to potentially identify an equivalent to a No-Observed-Adverse-Effect Level), 2 or 3 concentrations, to cover the range of proposed clinical doses, in addition to a vehicle and/or adjuvant control, should be used. At a minimum, the highest proposed human dose should be tested.

d. Number of proposed clinical inoculations plus one.

e. The period of study varies, depending on the frequency of dose administration (episodic, not daily), which may be abbreviated compared to the proposed clinical dosing schedule. The duration of the GLP safety studies is dependent on the study design. Tissue samples should be processed and data analyzed after intermediate and terminal sacrifice.

f. Timepoints for sacrifice: 1-3 days post-last inoculation; 2-4 weeks post-last inoculation (recovery).

g. A minimum of 5 animals per gender per dose should be included for each time point of sacrifice - this number may vary depending on animal model chosen.

h. Same route of administration as the proposed clinical route (with same delivery device, whenever possible).

i. Minimal endpoints examined should include:

- Daily clinical observations

- Weekly physical examinations

- Evaluation of injection site(s) for irritation (daily in the post-dose week) and histopathology

- Weekly body weights assessment

- Food and water consumption, body temperatures (daily in the week following inoculations)

- Ophthalmologic observations (pre-dosing and prior to sacrifice)

- Clinical pathology at regular intervals for hematology, serum chemistry, serology, urinalysis measurements

- Gross observations and organ weights at necropsy

- Histopathology evaluation to include a select tissue list, especially the immune function organs (e.g., lymph nodes), other highly perfused organs, and the genital organs in the control and high-dose animals and target tissues in the remaining groups. Depending on the route of inoculation, additional organs may need to be examined. (Full tissue collection and preservation should be performed even when only a select list is examined histopathologically)

- Relevant immunogenicity (humoral and/or cell mediated immune responses) studies

- Additional endpoints may be included to address therapeutic-specific concerns. Here, specialized studies to examine genetic toxicology (e.g., biodistribution) are strongly recommended. These are studies that may incorporate the use of assays that do not (yet) meet good laboratory practices standards. General recommendations include: tissue distribution studies, integration studies in tissues where the DNA vaccine remains at doses higher than those recommended guidances, immunotoxicity studies if repeated doses are planned in the clinical evaluation. 
Biodistribution studies may be waived for DNA vaccines produced by inserting a novel gene into a plasmid vector previously documented to have an acceptable biodistribution/integration profile. Biodistribution studies will still be necessary for DNA vaccines utilizing novel vectors, formulations, methods of delivery, routes of administration, or any other modifications expected to significantly impact cellular uptake and/or biodistribution. In every case, the decision should be consulted with the regulatory authorities. It is recommendable that manufacturers provide the complete sequence of the plasmid before initiating phase 1 clinical studies. Additional studies investigating multiple coding regions within the construct using multiplex PCR, confirming the integrity of extracted genomic DNA using housekeeping or constitutively expressed genes, carcinogenesis or tumorigenesis studies may be required if the vaccine is demonstrated to be integrated in tissues.

Consideration must be given to the possibility that the in vivo synthesized antigen may exhibit unwanted biological activity. If necessary, appropriate steps must be taken, e.g. by deletion mutagenesis, to eliminate this activity while retaining the desired immune response. If other gene constructs are included in the plasmid, such as antibiotic resistance genes for manufacturing reasons, then the possibility of expression of such gene sequences in mammalian cells or in micro-organisms which are potentially pathogenic, and the possible clinical consequences of such expression, should be considered.

When more than one type of vaccine is used in a sequential immunization protocol, if information supporting the safety and tolerability of the dose, schedule, and route of administration of each component proposed for use in the heterologous prime-boost regimen exist and data are deemed adequate to characterize the potential risks of the primeboost regimen to study participants, additional toxicology studies may not be necessary. However, this information should be submitted for consideration to the regulatory authorities that will evaluate the need for additional toxicology information to support the clinical plans (Guidance for Industry Considerations for Plasmid DNA Vaccines for Infectious Disease Indications, 2007).

If modifications to the manufacturing process or the DNA product are made during the development programme, the potential impact on the product should be considered. Modifications of the genetic sequence, the use of alternative promoter/enhancer sequences, or other changes to the product, may require additional non-clinical safety evaluation. Equally, if aspects related to the immunization protocol like the route of administration are changed, then additional non-clinical test should be done to assess the impact of these modifications. The scientific rationale for the approach taken should be provided (Guidance for Industry Considerations for Plasmid DNA Vaccines for Infectious Disease Indications, 2007).

The risk/benefit evaluation for a product is related to the actual product and its intended use. For example, a prophylactic DNA vaccine for use in healthy children will have a different risk/benefit ratio compared to a therapeutic DNA vaccine against cancer or a persistent pathogen like $\mathrm{HCV}$, for which there is no other available treatment or the efficacy of therapy is limited. Thus, for these and other reasons, it is likely that a flexible approach will be necessary for the non-clinical safety evaluation of DNA vaccines.

\section{Conclusions}

DNA vaccination is a continuously evolving and exciting field with many challenges to face. Methodological and regulatory frames are also developing every day. One important issue 
for a promising future in this vaccination strategy is to demonstrate efficacy in humans in a safe context. In this scenario, the pre-clinical protocols are very relevant and should be based on the design of the proposed clinical assessment. General regulatory frames rule the administration of exogenous substances, but given the nature and proposed mechanism of action for DNA vaccines additional specific considerations should be taken into account. Safety evaluation of DNA vaccines against infectious diseases should be carried out considering the particular characteristics of the disease and the causal pathogen, including the expected use, preventive or therapeutic, and target population, in a case by case approach. Fortunately, no major adverse events have been observed so far after DNA immunization in humans on clinical trials. The establishment of strong tests for releasing the product is very relevant in lots consistency and reproducibility of results at both pre-clinical and clinical level. New frontiers are opening and attention should be given to novel preparations including original adjuvants/immunostimulatory molecules or employing modern delivery vehicles for DNA vaccines, as well as the long-term pharmaco-vigilance.

\section{Acknowledgments}

Authors would like to thank Liz Alvarez-Lajonchere, Dioslaida Urquiza, Jeny Marante, Ariel Vina, Maylin Pupo, Lizet Aldana, Yordanka Soria, Juan Romero, Roberto Madrigal, Leticia Martinez, Miladys Limonta, Marbelis Linares, Dinorah Torres, Gabriel Marquez, Marta Pupo, Eduardo Martínez, Verena Muzio, Gerardo Guillén, Idania Gonzalez, Gillian Martínez, Ivis Guerra and Angel Pérez for the contribution to this work.

\section{References}

Acosta-Rivero, N., Aguilera, Y., Falcon, V., Poutou, J., Musacchio, A. \& Alvarez-Lajonchere, L. (2006) Ultrastructural and immunological characterization of hepatitis C core protein-dna plasmid complexes. Am. J. Immunol. Vol 2, pp. 67-72.

Alvarez-Lajonchere, L. \& Dueñas-Carrera, S. (2009). Advances in DNA immunization against hepatitis $C$ virus infection: Opportunities and challenges. Hum. Vaccin. Vol 5, pp. 568-571.

Alvarez-Lajonchere, L., Shoukry, N.H., Grá, B., Amador-Cañizares, Y., Helle, F., Bédard, N., Guerra, I., Drouin, C., Dubuisson, J., González-Horta, E.E., Martínez, G., Marante, J., Cinza, Z., Castellanos, M., Dueñas-Carrera, S. (2009). Immunogenicity of CIGB230, a therapeutic DNA vaccine preparation, in HCV-chronically infected individuals in a Phase I clinical trial. J. Viral Hepat. Vol 16, pp. 156-167.

Alvarez-Lajonchere, L., Gonzalez, M., Alvarez-Obregon, J.C., Guerra, I., Viña, A., AcostaRivero, N., Musacchio, A., Morales, J. \& Dueñas-Carrera, S. (2006). Hepatitis C virus $(\mathrm{HCV})$ core protein enhances the immunogenicity of a co-delivered DNA vaccine encoding HCV structural antigens in mice. Biotechnol. Appl. Biochem. Vol 44, pp. 9-17.

Armengol, G., Ruiz, L.M. \& Orduz, S. (2004). The injection of plasmid DNA in mouse muscle results in lifetime persistence of DNA, gene expression, and humoral response. Mol. Biotechnol. Vol 27, pp. 109-118.

Bacardí, D., Amador-Cañizares, Y., Cosme, K., Urquiza, D., Suárez, J., Marante, J., Viña, A., Vázquez, A., Concepción, J., Pupo, M., Aldana, L., Soria, Y., Romero, J., Madrigal, R., Martínez, L., Hernández, L., González, I. \& Dueñas-Carrera, S. 2009. Toxicology 
and biodistribution study of CIGB-230, a DNA vaccine against hepatitis C virus. Hum. Exp. Toxicol. Vol 2, pp.479-491.

Buckland, B.C. (2005) The process development challenge for a new vaccine. Nat. Med. Vol 11, pp. S16 - S19.

Bureau, M.F., Naimi, S., Torero, I.R., Seguin, J., Georger, C. \& Arnould, E. (2004). Intramuscular plasmid DNA electrotransfer: biodistribution and degradation. Biochim. Biophys. Acta. Vol 1676, pp. 138-148.

Castellanos, M., Cinza, Z., Dorta, Z., Veliz, G., Vega, H., Lorenzo, I., Ojeda, S., DueñasCarrera, S., Alvarez-Lajonchere, L., Martínez, G., Ferrer, E., Limonta, M., Linares, M., Ruiz, O., Acevedo, B., Torres, D., Márquez, G., Herrera, L. \& Arús, E. (2010) Immunization with a DNA vaccine candidate in chronic hepatitis $C$ patients is safe, well tolerated and does not impair immune response induction after anti-hepatitis B vaccination. J. Gene Med. Vol 12, pp. 107-116.

Chan, P.K. \& Hayes, A.W. (2001). Acute Toxicity and Eye Irritancy. In: Principles and Methods of Toxicology. Fourth Edition, edited by A. Wallace Hayes, pp. 853-915, Raven Press, Ltd., New York.

Coelho-Castelo, A.A., Trombone, A.P., Rosada, R.S., Santos, Jr., R.R., Bonato, V.L \& Sartori, A. (2006). Tissue distribution of a plasmid DNA encoding Hsp65 gene is dependent on the dose administered through intramuscular delivery. Genet. Vaccines Ther. Vol 4, pp. 1.

Contrera, J.F., Aub, D., Barbehenn, E., Belair, E., Chen, C., Evoniuk, G., Mainigi, K., Mielach, F., Sancilio, L. (1993). A retrospective comparison of the results of 6 and 12 month non-rodent toxicity studies. Adverse Drug React Toxicol Rev. Vol 12, pp. 63-76.

Dean, J.H., Hincks, J.R. \& Remandet, B. (1998). Immunotoxicology assessment in the pharmaceutical industry. Toxicol. Lett. Vol 102-103, pp. 247-255.

Food and Drug Administration (FDA). Center for Drug evaluation and Research (CDER). (1996). Guidance for industry. Single Dose Acute Toxicity Testig for Pharmaceuticals.

Ghany, M.G., Strader, D.B., Thomas, D.L. \& Seeff, L.B. (2009). Diagnosis, management, and treatment of hepatitis C: an update. Hepatology. Vol 49, pp. 1335-1374.

Glenting J \& Wessels S. (2005). Ensuring safety of DNA vaccines. Microb. Cell Fact. Vol 4, pp. 26.

Good manufacturing practices for biological products. (1992). In: WHO Expert Committee on Biological Standardization. Forty-second report. Geneva, World Health Organization, Annex 1 (WHO Technical Report Series, No. 822).

Good manufacturing practices for pharmaceutical products. (2003). In: WHO Expert Committee on Specifications for Pharmaceutical Preparations. Thirty-seventh report. Geneva, World Health Organization, Annex 4 (WHO Technical Report Series, No. 908).

Granham, C.E. (1987) Overview: the industry position. In: Preclinical safety of Biotecnology Products Intended for human use. edited by C.E. Graham Alan R. pp 183-187. Liss, New York.

Greaves, P. (2000). Histopathology of Preclinical Toxicity Studies. Interpretation and relevance in Grug Safety Evaluation. Second Edition. ELSEVIER. 
U.S. Department of Health and Human Services, Food and Drug Administration, Center for Biologics Evaluation and Research. (2007). Guidance for Industry Considerations for Plasmid DNA Vaccines for Infectious Disease Indications.

Guidelines for assuring the quality and nonclinical safety evaluation of DNA vaccines. (2005). In: WHO Expert Committee on Biological Standardization. (WHO Technical Report Series, No. 941).

Guidelines for assuring the quality of DNA vaccines. (1998). In: WHO Expert Committee on Biological Standardization. Forty-seventy report, Geneva, World Health Organization, Annex 3 (WHO Technical Report Series, No. 878).

Guidelines on clinical evaluation of vaccines: regulatory expectations. (2004). In: WHO Expert Committee on Biological Standardization. Fifty-second report. Geneva, World Health Organization, Annex 1 (WHO Technical Report Series, No. 924).

Guidelines on nonclinical evaluation of vaccines. (2006). In: WHO Expert Committee on Biological Standardization. Geneva, World Health Organization, Annex 1 (WHO Technical Report Series, No. 932).

Hastings, K. (2002). Implications of the new FDA/CDER immunotoxicology guidance for drugs. Int. Immunopharmacol. Vol 2, pp. 1613-1618.

Hohlweg, U. \& Doerfler, W. (2001). On the fate of plant or other foreign genes upon the uptake in food or after intramuscular injection in mice. Mol. Genet. Genomics. Vol 265, pp. 225-233.

ICH. (1995). Need for Carcinogenicity Studies Pharmaceuticals, Topic S1A, Step 5, ICH Harmonized Tripartite Guideline, International Conference in Harmonization of Technical Requirements for Registration of Pharmaceuticals for Human Use, Geneva, Switzerland.

ICH. (1996). Detection of Toxicity to Reproduction from Medicinal Products, Topic S5A, Step 5, ICH Harmonized Tripartite Guideline, International Conference in Harmonization of Technical Requirements for Registration of Pharmaceuticals for Human Use, Geneva, Switzerland

ICH. (1996). Reproductive Toxicity: Male Fertility Studies, Topic S5B, Step 5, ICH Harmonized Tripartite Guideline, International Conference in Harmonization of Technical Requirements for Registration of Pharmaceuticals for Human Use, Geneva, Switzerland.

ICH. (1997). Preclinical safety Evaluation of Biotechnology-Derived Pharmaceuticals, Topic S6, Step 5, ICH Harmonized Tripartite Guideline, International Conference in Harmonization of Technical Requirements for Registration of Pharmaceuticals for Human Use, Geneva, Switzerland.

ICH M3 (M). (2000). No-clinical safety studies for the conduct of Human clinical trials for pharmaceuticals (modification of CPMP/ICH/286/95), EMEA.

Jeong, G.J., Byun, H.M., Kim, J.M., Yoon, H., Choi, H.G. \& Kim, W.K. (2007). Biodistribution and tissue expression kinetics of plasmid DNA complexed with polyethylenimines of different molecular weight and structure. J. Control Release. Vol 118, pp. 118-125.

Kim, B.M., Lee, D.S., Chol, J.H., Kim, C.Y., Son, M., Suh, Y.S., Baek, K.H., Park, K.S., Sung, Y.C. \& Kim, W.B. (2003). In vivo kinetics and biodistribution of a HIV-1 DNA vaccine after administration in mice. Arch. Pharm. Res. Vol 26, pp. 493-498.

Kobayashi, N., Kuramoto, T., Yamaoka, K., Hashida, M. \& Takakura, Y. (2001). Hepatic uptake and gene expression mechanisms following intravenous administration of 
plasmid DNA by conventional and hydrodynamics based procedures. J. Pharmacol. Exp. Ther. Vol 297, pp. 853-860.

Kovarik, J. \& Siegrist, C.A. (2001). The search for novel adjuvants for early life vaccinations: can "danger" motifs show us the way? Arch. Immunol. Ther. Exp. (Warsz). Vol 49, pp. 209-215.

Ledwith, B.J., Manam, S., Troilo, P.J., Barnum, A.B., Pauley, C.J., Griffiths, I., Ind, T.G., Harper, L.B., Beare, C.M., Bagdon, W.J. \& Nichols, W.W. (2000). Plasmid DNA vaccines: Investigation of integration into host cellular DNA following intramuscular injection in mice. Intervirology. Vol 43, pp. 258-272.

Litvinov, S. (2009). New adjuvants for accelerated and enhanced antibody response. Nat Meth. Vol 6, pp. 10-11.

Loeb, W.F., Bannerman, R.M.., Rininger, B.F. \& Johnson, A.J. (1978). Haematological disorders in: Pathology of laboratory animals. Edited by Benirschke K, Garner FM \& Jones JC, Vol 1. Chap. 11. pp 889-1050. Springer vervac. New York.

Liu, M.A. (2011). DNA vaccines: an historical perspective and view to the future. Immunol. Rev. Vol 239, pp.62-84.

Manam, S., Ledwith, B.J., Barnum, A.B., Troilo, P.J., Pauley, C.J., Harper, L.B., Griffiths, I., Ind, T.G., Niu, Z., Denisova, L., Follmer, T.T., Pacchione, S.J., Wang, Z., Beare, C.M., Bagdon, W.J. \& Nichols, W.W. (2000). Plasmid DNA vaccines: Tissue distribution and effects of DNA sequence, adjuvants and delivery method on integration into host DNA. Intervirology. Vol 43, pp. 273-281.

Guidelines of the quality, safety and efficacy of medical products for use. The principles governing medical products to the European Community. (1992). Non-clinical local tolerance testing of medical products. Addendum No. 2. Vol. III: 137-48.

OECD, Guidelines for testing of chemicals. (1993). Section 4: Health Effects. "Acute Oral Toxicity", No. 401. France.

Oh, Y.K., Kim, J.P., Hwang, T.S., Ko, J.J., Kim, J.M. \& Yang, J.S. (2001). Nasal absorption and biodistribution of plasmid DNA: an alternative route of DNA vaccine delivery. Vaccine. Vol 19, pp. 4519-4525.

Pal, R., Yu, Q., Wang, S., Kalyanaraman, V.S., Nair, B.C. \& Hudacik, L. (2006). Definitive toxicology and biodistribution study of a polyvalent DNA prime/protein boost human immunodeficiency virus type 1 (HIV-1) vaccine in rabbits. Vaccine. Vol 24, pp. 1225-1234.

Parker, S.E., Borellini, F., Wenk, M.L., Hobart, P., Hoffman, S.L., Hedstrom, R., Le, T. \& Norman, J.A. (1999). Plasmid DNA malaria vaccine: Tissue distribution and safety studies in mice and rabbits. Hum. Gene Ther. Vol 10, pp. 741-758.

Quezada, A., Larson, J., French, M., Ponce, R., Perrard, J., Durland, R. (2004). Biodistribution and safety studies of hDel-1 plasmid-based gene therapy in mouse and rabbit models. J. Pharm. Pharmacol. Vol 56, pp. 177-185.

Committe for Propietary Medicinal Products. EMEA. (1998). Safety Studies for Gene Therapy Products. CPMP/SWP/112/98.

Stoll, R.E. (1987). The preclinical development of biotechnology-derived pharmaceuticals: The PMA perspective. In: Preclinical Safety of Biotechnology products intended for human use. Edited by C.E. Graham. pp 169-171. Alan R. Liss, New York, 
Tuomela, M., Malm, M., Wallen, M., Stanescu, I., Krohn, K. \& Peterson, P. (2005). Biodistribution and general safety of a naked DNA plasmid, GTU® - MultiHIV, in a rat using a quantitative PCR method. Vaccine Vol 23, pp. 890-896.

Wang, Z., Troilo, P.J., Wang, X., Griffiths, T.G., Pacchione, S.J., Barnum, A.B., Harper, L.B., Pauley, C.J., Niu, Z., Denisova, L., Follmer, T.T., Rizzuto, G., Ciliberto, G., Fattori, E., Monica, N.L., Manam, S. \& Ledwith, B.J. (2004). Detection of integration of plasmid DNA into host genomic DNA following intramuscular injection and electroporation. Gene Ther. Vol 11, pp. 711-721.

Wolff, J.A., Ludtke, J.J., Acsadi, G., Williams, P. \& Jani, A. (1992). Long-term persistence of plasmid DNA and foreign gene expression in mouse muscle. Hum. Mol. Genet. Vol 1, pp. 363-369. 


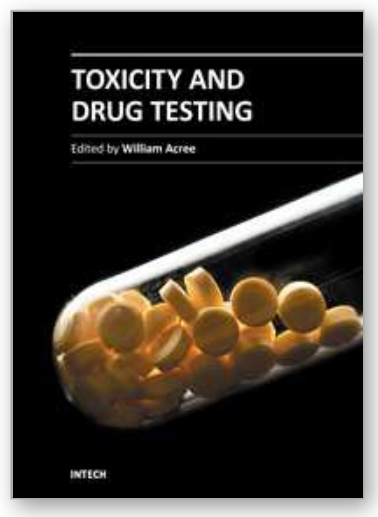

\author{
Toxicity and Drug Testing \\ Edited by Prof. Bill Acree
}

ISBN 978-953-51-0004-1

Hard cover, 528 pages

Publisher InTech

Published online 10, February, 2012

Published in print edition February, 2012

Modern drug design and testing involves experimental in vivo and in vitro measurement of the drug candidate's ADMET (adsorption, distribution, metabolism, elimination and toxicity) properties in the early stages of drug discovery. Only a small percentage of the proposed drug candidates receive government approval and reach the market place. Unfavorable pharmacokinetic properties, poor bioavailability and efficacy, low solubility, adverse side effects and toxicity concerns account for many of the drug failures encountered in the pharmaceutical industry. Authors from several countries have contributed chapters detailing regulatory policies, pharmaceutical concerns and clinical practices in their respective countries with the expectation that the open exchange of scientific results and ideas presented in this book will lead to improved pharmaceutical products.

\title{
How to reference
}

In order to correctly reference this scholarly work, feel free to copy and paste the following:

Dania Bacardí, Karelia Cosme, José Suárez, Yalena Amador-Cañizares and Santiago Dueñas-Carrera (2012). Evaluation of Drug Toxicity for DNA Vaccine Candidates Against Infectious Diseases: Hepatitis C as Experimental Model, Toxicity and Drug Testing, Prof. Bill Acree (Ed.), ISBN: 978-953-51-0004-1, InTech, Available from: http://www.intechopen.com/books/toxicity-and-drug-testing/evaluation-of-drug-toxicity-for-dnavaccine-candidates-against-infectious-diseases-hepatitis-c-as-ex

\section{INTECH}

open science | open minds

\section{InTech Europe}

University Campus STeP Ri

Slavka Krautzeka 83/A

51000 Rijeka, Croatia

Phone: +385 (51) 770447

Fax: +385 (51) 686166

www.intechopen.com

\section{InTech China}

Unit 405, Office Block, Hotel Equatorial Shanghai

No.65, Yan An Road (West), Shanghai, 200040, China

中国上海市延安西路65号上海国际贵都大饭店办公楼 405 单元

Phone: +86-21-62489820

Fax: $+86-21-62489821$ 
(C) 2012 The Author(s). Licensee IntechOpen. This is an open access article distributed under the terms of the Creative Commons Attribution 3.0 License, which permits unrestricted use, distribution, and reproduction in any medium, provided the original work is properly cited. 